http://dx.doi.org/10.1590/1678-4162-7928

Arq. Bras. Med. Vet. Zootec., v.68, n.2, p.353-360, 2016

\title{
Morfo-histologia dos pulmões e árvore bronquial de Procyon cancrivorus (Carnivora: Procyonidae)
}

\author{
[Morphohistology of the lungs and bronchial tree of the Procyon cancrivorus \\ (Carnivora: Procyonidae)] \\ J.F.F.S. Paranaíba ${ }^{1}$, F.C. Lima $^{1}$, D.K.S. Pereira ${ }^{1}$, E.G. Araújo ${ }^{2}$, K.F. Pereira ${ }^{1 *}$ \\ ${ }^{1}$ Universidade Federal de Goiás - Regional Jataí - Jataí, GO \\ ${ }^{2}$ Escola de Veterinária e Zootecnia - Universidade Federal de Goiás - Regional Goiânia- Goiânia, GO
}

\section{RESUMO}

Nenhuma característica dos seres vivos é tão primordial quanto a respiração, e os pulmões são os principais órgãos do sistema respiratório. Este estudo tem por objetivo descrever os aspectos macroscópicos da traqueia, dos brônquios e dos lobos pulmonares bem como os aspectos microscópicos dos brônquios pulmonares do mão-pelada e compará-los com dados da literatura de estudos realizados com mamíferos silvestres e domésticos. Utilizaram-se três exemplares de Procyon cancrivorus, que foram fixados em solução aquosa de formaldeído a $10 \%$. Os pulmões e a traqueia foram dissecados e fotografados com câmera fotográfica digital (Câmera Sony a200, 10.2mpx). Para a identificação das características microscópicas, foram coletados fragmentos de cada brônquio seguindo as técnicas de rotina histológica. O pulmão do Procyon cancrivorus se divide em quatro lobos direito e dois lobos esquerdo e a traqueia apresenta cerca de 31 a 34 anéis. Os brônquios extrapulmonares se dividem em direito e esquerdo; o direito se subdivide em brônquios lobares cranial, médio, acessório e caudal, e o esquerdo em lobares cranial e caudal, com seus respectivos brônquios segmentares. Microscopicamente, os brônquios apresentam um epitélio prismático pseudoestratificado ciliado com células caliciformes e feixes de fibras de musculatura lisa, placas de cartilagem hialina e fibras elásticas. O conhecimento da morfologia desses órgãos nas espécies silvestres auxilia em estudos descritivos e/ou comparativos entre espécies.

Palavras-chave: anatomia, brônquios, mão-pelada, traquéia

\begin{abstract}
No characteristic of living beings is as primal as breathing, and the lungs are the main organs in the respiratory system. This study aims to describe the macroscopic aspects of the trachea, bronchus and lung lobes and microscopic aspects of the bronchi of raccoon lungs and compare with data from the literature studies performed with wild and domestic mammals. We used three samples of Procyon cancrivorus, which were fixed in aqueous 10\% formaldehyde, lungs and trachea were dissected and photographed with a digital camera (Sony a200 Camera, 10.2mpx). For the identification of microscopic characteristics, fragments were collected from each bronchus following routine histological techniques. The Procyon cancrivorus lung is divided into four lobes, with two right and left lobes. The trachea has about 31-34 rings. The extrapulmonary bronchi divides into left and right, where the right is divided into lobar bronchi cranial, middle, accessory and caudal lobes and the left in cranial and caudal, with their respective segmental bronchi. Microscopically the bronchial epithelium has prismatic pseudo-ciliated and goblet cells with bundles of smooth muscle fibers, plates of hyaline cartilage and elastic fibers. Knowledge of the morphology of these organs in wild species helps us in descriptive studies and / or comparisons between species.
\end{abstract}

Keywords:Anatomy,bronchi, raccoon, trachea

Recebido em 22 de agosto de 2014

Aceito em 24 de novembro de 2015

*Autor para correspondência (corresponding author)

E-mail: kpereiraufg@gmail.com 


\section{INTRODUÇÃO}

Procyon cancrivorus (Cuvier, 1798) possui uma distribuição geográfica ampla, de ocorrência neotropical desde a América Central (Costa Rica e Panamá) até o Uruguai, nordeste da Argentina e Brasil. Em território brasileiro, ocorre em todos os biomas (Câmara e Murta, 2003; Cubas et al., 2006).

É um carnívoro silvestre, podendo chegar a $1 \mathrm{~m}$ de comprimento, incluindo a cauda, e pesar até $10 \mathrm{~kg}$. Apresenta uma pelagem variando a coloração do marrom escuro ao grisalho, sendo prontamente identificado com uma máscara preta que se estende dos olhos à base da mandíbula e possui cauda longa, peluda e com listras formando de cinco a 10 anéis escuros (Câmara e Murta, 2003; Cubas et al., 2006).

São animais noturnos e crepusculares de vida solitária, bastante rústicos e resistentes às variações climáticas. De hábitos terrestres, preferem se abrigar em tocas no chão, são também habitantes de áreas arbustivas, preferencialmente próximas a cursos de água (Pellanda et al., 2010). Apresentam ótimas habilidades para cavar, nadar e escalar, subir em árvores para buscar presas, refugiar-se de eventuais predadores, repousar e nidificar (Cubas et al., 2006).

Nenhuma característica dos seres vivos é tão primordial quanto a respiração, pois o sistema respiratório, além de conduzir e fazer as trocas gasosas, auxilia também na fonação, na olfação, na regulação da temperatura corporal e na excreção. Esse sistema é subdividido em porção condutora, de transição e respiratória (Banks, 1991). A traqueia é um órgão tubular cartilaginoso, flexível e membranoso, que se estende da laringe até os brônquios primários extrapulmonares. Nos anéis traqueais, a cartilagem tem forma de ferradura onde as extremidades abertas são preenchidas por musculatura lisa (Getty,1986). Os brônquios extrapulmonares ou primários passam caudolateralmente da bifurcação da traqueia, na carina, e penetram no pulmão. Estruturalmente, são semelhantes à traqueia (Getty,1986; Banks, 1991).
Os pulmões são os órgãos respiratórios direito e esquerdo, que ocupam grande parte da caixa torácica. A pleura pulmonar reveste os pulmões, que são invaginados no saco ipsilateral. $O$ pulmão direito de carnívoros é constituído por lobos cranial, médio, caudal e acessório. $\mathrm{O}$ pulmão esquerdo é subdividido em lobo cranial (partes cranial e caudal) e lobo caudal (Evans e De Lahunta, 1994; Dyce et al., 1997). Os brônquios intrapulmonares são divididos em primários secundários e terciários. Os intrapulmonares primários são continuação dos brônquios extrapulmonares; seus constituintes são semelhantes, e os intrapulmonares secundários e terciários se diferenciam pela ramificação, pelo tamanho da luz e pelos constituintes da parede (Banks, 1991).

A morfologia do P. cancrivorus foi descrita em pesquisas acerca da musculatura, dos sistemas nervoso, vascular, dentre outros (Pereira et al., 2010a,b, 2011, 2012, 2013), entretanto a literatura sobre o sistema respiratório é escassa. Assim, o presente trabalho teve como objetivo descrever os aspectos macroscópicos da traqueia, dos brônquios e dos lobos pulmonares e os aspectos microscópicos dos brônquios pulmonares do mão-pelada, que subsidiam o estudo descritivo de uma espécie, para comparação entre espécies que apresentem semelhanças morfológicas.

\section{MATERIAL E MÉTODOS}

Para a descrição da morfologia da traqueia, dos brônquios e dos lobos pulmonares do $P$. cancrivorus, foram utilizados três exemplares adultos, machos, procedentes de coleta em rodovias (mortos por acidentes) cujos critérios obedeceram ao Comitê de Ética no Uso de Animais (CEUA) e à lei vigente que regulamenta a experimentação animal (Lei 1.153/95).

Análise macroscópica: os animais foram fixados pelos processos de perfusão, mediante injeção de solução aquosa de formaldeído a $10 \%$ por meio da veia jugular externa, e de imersão no mesmo fixador. A seguir, a caixa torácica foi aberta, os órgãos de interesse foram expostos, dissecados, descritos e fotografados com câmera fotográfica digital (Câmera Sony a200, 10.2mpx) no Laboratório de Anatomia Humana e Comparativa da Universidade Federal de Goiás Regional Jataí. 


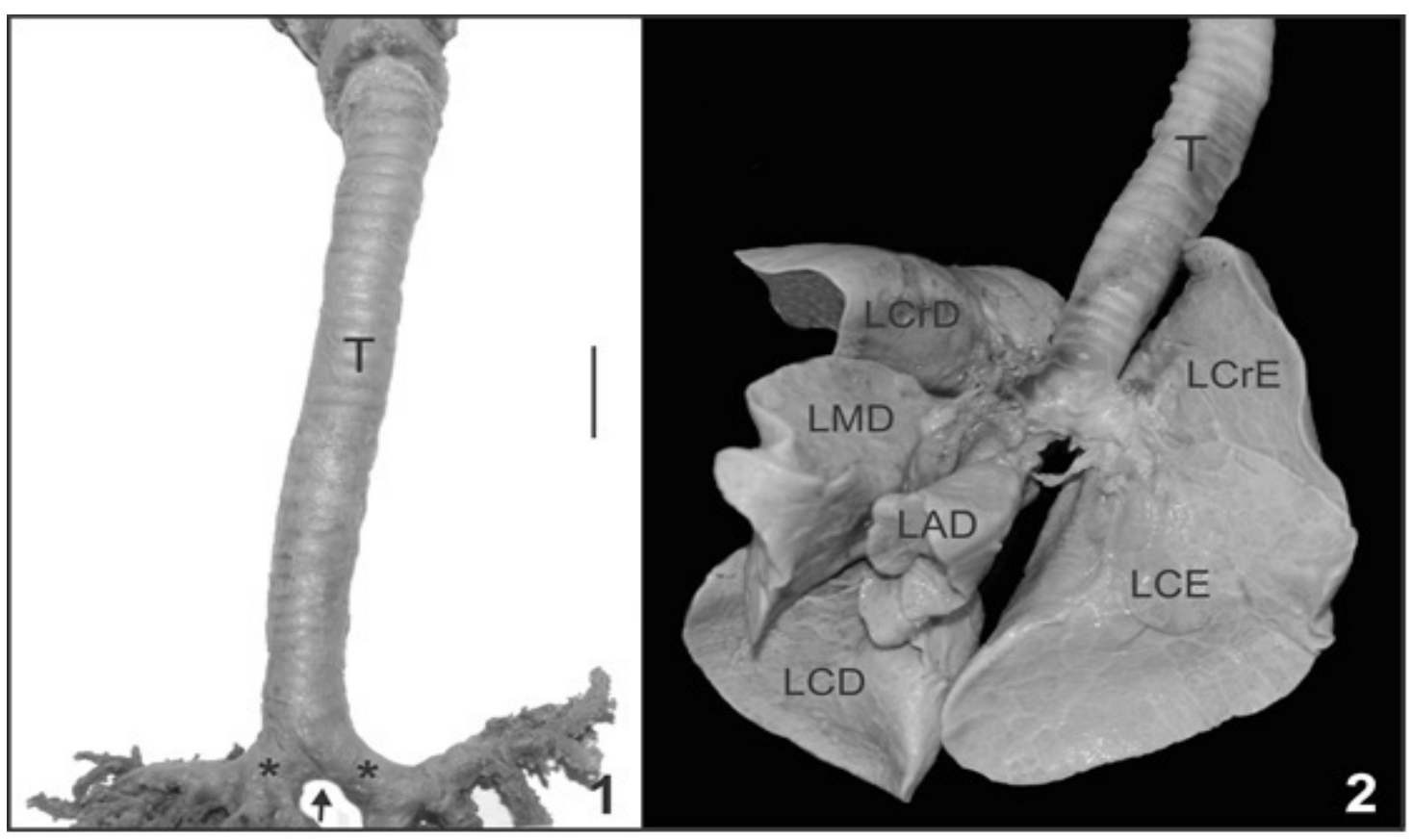

Análise microscópica: para a identificação das características microscópicas, foram coletados fragmentos de cada brônquio. Esses fragmentos foram processados e incluídos em blocos de parafina, cortados em um micrótomo Leica RM 2245 , com espessura média de $5 \mu \mathrm{m}$, e os cortes corados seguindo as técnicas de hematoxilina/eosina (HE). As lâminas foram montadas com Entellan e lamínulas, analisadas e fotografadas por meio de um fotomicroscópio Olympus CX41 com conjunto de imagem Olympus SC30.

A nomenclatura utilizada foi referida conforme o International Commitee on Veterinary Gross Anatomical Nomenclature (2012).

\section{RESULTADOS E DISCUSSÃO}

O comprimento da traqueia é impreciso. O órgão é composto por uma porção cartilaginosa formada por anéis traqueais, que variam de forma quantitativa entre espécies, e por uma porção membranosa, constituída pelo músculo traqueal. A traqueia do $P$. cancrivorus apresenta uma variação de 31 a 34 anéis (Fig.1). Segundo Getty (1986), a traqueia do cão tem uma variação de 42 a 46 anéis traqueais, enquanto a dos gatos possui entre 38 a 43; em suínos das raças Landrace, Large-white e Hampshire, o número de anéis traqueais varia de 28 a 40 (Santana et al., 2002) e em ratos gigantes africanos os anéis traqueais variam de 21 a 33 (Ibe et al., 2011a).

Figuras 1, 2. Fotografia da traqueia (1) e pulmões (2) de $P$. cancrivorus.Traqueia (T), carina (seta), bifurcação no brônquio extrapulmonar direito e esquerdo (*), lobo cranial direito (LCrD), lobo médio direito (LMD), lobo acessório direito (LAD), lobo caudal direito (LCD), lobo cranial esquerdo (LCrE) e lobo caudal esquerdo (LCE). Barra: $5 \mathrm{~cm}$.

O pulmão é dividido externamente por fissuras bastante evidentes correspondendo às divisões dos lobos, tanto à direita quanto à esquerda. $\mathrm{O} P$. cancrivorus apresenta o pulmão direito dividido em lobo cranial, lobo médio, lobo caudal e lobo acessório (Fig. 2), corroborando os achados de Santos et al. (2013) para mão-pelada, assim como cão e gato (Getty, 1986), cutia (Penno et al., 2005) gato mourisco (Santos A.L. Q. et al., 2011), coelho (Barone, 1997), quati (Santos, 2012) e rato gigante africano (Ibe et al., 2011a).

Essa morfologia se diferencia da paca (Rehder et al., 2008), que apresenta o lobo médio com segmentos cranial e caudal, dos ovinos e da chinchila (Borges et al., 2002; Pereira et al., 2005), com o lobo cranial dividido em segmentos cranial e caudal, e da capivara (Citrângulo et al., 2001), com o lobo acessório direito subdividido (Tab. 1). 
Paranaíba et al.

Tabela 1. Divisão dos lobos pulmonares em diversas espécies

\begin{tabular}{|c|c|c|c|c|c|c|c|}
\hline \multirow{3}{*}{ Espécie } & \multicolumn{4}{|c|}{ Pulmão Direito } & \multicolumn{3}{|c|}{ Pulmão Esquerdo } \\
\hline & \multicolumn{7}{|c|}{ Brônquios lobares/Brônquios segmentares $\left(\mathrm{n}^{\circ}\right)$} \\
\hline & Cranial & Médio & Caudal & Acessório & Cranial & Caudal & Acessório \\
\hline P. cancrivorus ${ }^{1}$ & $01 / 06$ & $01 / 02$ & $01 / 06$ & $01 / 03$ & $01 / 05$ & $01 / 03$ & \\
\hline P. cancrivorus ${ }^{2}$ & $01 / 06$ & $01 / 02$ & $01 / 02$ & $01 / 03$ & $01 / 05$ & $01 / 03$ & \\
\hline P. cancrivorus ${ }^{3}$ & $01 / 02$ & $01 / 02$ & $02 /-$ & $01 / 02$ & $01 / 03$ & $01 / 02$ & \\
\hline Cão & $01 /-$ & $01 /-$ & $01 /-$ & $01 /-$ & $01 / 02$ & $01 / 02$ & \\
\hline Cutia & $01 / 02-12$ & $\begin{array}{l}01 / 06- \\
11\end{array}$ & $\begin{array}{l}01 / 05- \\
09\end{array}$ & $01 / 02$ & $01 /-$ & $\begin{array}{l}01 / 05- \\
07\end{array}$ & \\
\hline Gato mourisco & $01 / 02$ & $01 / 02$ & $01 / 05$ & $01 / 02$ & $01 / 02$ & $01 / 05$ & \\
\hline Ovino & 02traqueal & $01 /-$ & $01 /-$ & $01 /-$ & $01 /-$ & $01 /-$ & \\
\hline Paca & $01 /-$ & $01 / 02$ & $02 /-$ & $01 /-$ & $01 /-$ & $03 /-$ & $01 /-$ \\
\hline
\end{tabular}

O pulmão esquerdo se divide em lobo cranial e lobo caudal (Fig. 2), também encontrado por Santos et al. (2013) para mão-pelada, assemelhando-se com o quati (Santos, 2012) e diferindo do cão e do gato (Getty, 1986; Dyce et al., 1997), da cutia (Penno et al., 2005), do ovino (Borges et al., 2002), do gato mourisco (Santos A. L. Q. et al., 2011), do coelho (Barone, 1997), da chinchila (Pereira et al., 2005) e da capivara (Citrângulo et al., 2001), que apresentam uma divisão no lobo cranial com parte cranial e parte caudal, da paca (Rehder et al., 2008), que apresenta três lobos pulmonares, e do rato gigante africano (Ibe et al., 2011a), que não apresenta divisões no pulmão esquerdo. A Tab. 1 apresenta um resumo das principais características de lobação do pulmão dos mamíferos.

A distribuição da árvore brônquica do $P$. cancrivorus se dá a partir dos brônquios principais (extrapulmonares), advindos da bifurcação da traqueia na região da carina, ramificando-se conforme sua distribuição pelo pulmão. Os brônquios extrapulmonares (primários) se ramificam emitindo ramos para os quatro lobos do pulmão direito e para os dois lobos do pulmão esquerdo. Esses ramos são denominados brônquios lobares. Cada brônquio lobar (secundário) se ramifica, dando origem a vários brônquios segmentares (terciários) (Fig. 3). Esses dados também foram encontrados no estudo prévio realizado por Sestari et al. (2011) e Santos et al. (2013) em mão-pelada e corroboram os achados para quati (Santos A. C. et al., 2011;
Santos, 2012), carnívoros domésticos, como cão e gato (Banks, 1991; Samuelson, 2007), e ratos gigantes africanos (Ibe et al., 2011a).

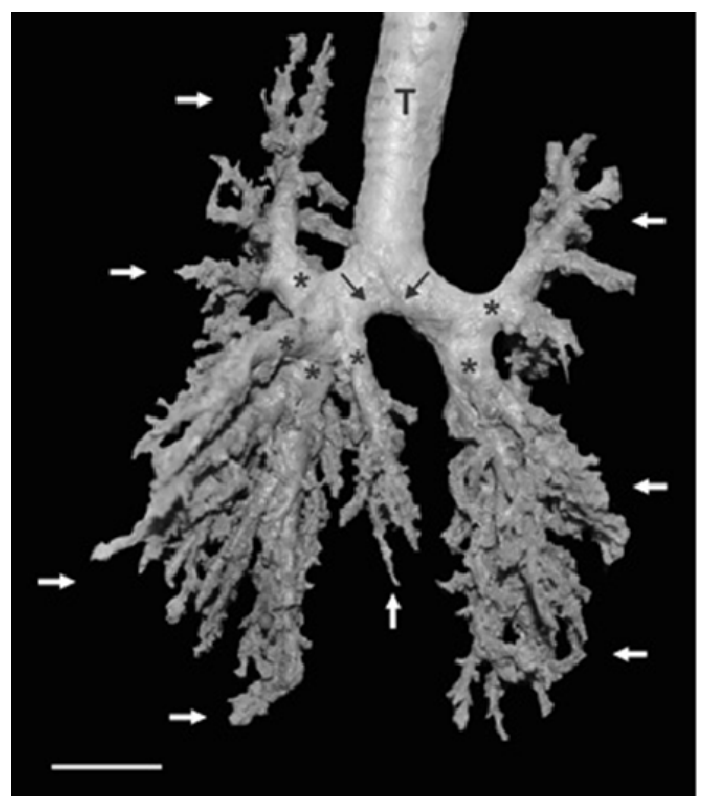

Figura 3. Fotografia da árvore brônquica de $P$. cancrivorus. Traqueia (T), brônquios extrapulmonares direito e esquerdo (setas pretas), brônquios lobares (*) e brônquios segmentares (setas brancas). Barra: $4 \mathrm{~cm}$.

Para o pulmão direito do $P$. cancrivorus, o brônquio extrapulmonar emite um brônquio lobar que se dirige para o lobo cranial direito e ramifica-se em brônquios segmentares. Esses dados corroboram os achados de Rehder et al. (2008) para paca e de Getty (1986) e Dyce et al. 
(1997) para carnívoros domésticos e diferem daqueles encontrados para cutia (Penno et al., 2005) e gato mourisco (Santos A. L. Q. et al., 2011), que apresentam uma bifurcação deste brônquio em segmentos cranial e caudal do lobo, e para ovinos (Borges et al., 2002), nos quais este lobo é ventilado pelo brônquio traqueal e não pelo extrapulmonar. Os ovinos, os ruminantes e os suínos apresentam um brônquio traqueal separado, que surge proximal à bifurcação da traqueia e promove aeração isolada do lobo cranial do pulmão direito (Dyce et al., 1997). Esse dado não foi observado em $P$. cancrivorus.

Tabela 2. Divisões dos brônquios lobares e segmentares direito e esquerdo em diversas espécies. 1, esta investigação; 2, Santos et al. (2013); 3, Sestari et al., 2011

\begin{tabular}{|c|c|c|c|c|c|c|c|}
\hline \multirow{2}{*}{ Espécie } & \multicolumn{4}{|c|}{ Pulmão Direito } & \multicolumn{3}{|c|}{ Pulmão Esquerdo } \\
\hline & Cranial & Médio & Caudal & Acessório & Cranial & Caudal & Acessório \\
\hline P. cancrivorus ${ }^{1}$ & $\mathrm{x}$ & $\mathrm{x}$ & $\mathrm{x}$ & $\mathrm{x}$ & $\mathrm{x}$ & $\mathrm{x}$ & \\
\hline Quati & $\mathrm{x}$ & $\mathrm{x}$ & $\mathrm{x}$ & $\mathrm{x}$ & $\mathrm{x}$ & $\mathrm{x}$ & \\
\hline Cão & $\mathrm{x}$ & $\mathrm{x}$ & $\mathrm{x}$ & $\mathrm{x}$ & $\mathrm{Cra} / \mathrm{Cau}$ & $\mathrm{x}$ & \\
\hline Gato & $\mathrm{x}$ & $\mathrm{x}$ & $\mathrm{x}$ & $\mathrm{x}$ & $\mathrm{Cra} / \mathrm{Cau}$ & $\mathrm{x}$ & \\
\hline Cutia & $\mathrm{x}$ & $\mathrm{x}$ & $\mathrm{x}$ & $\mathrm{x}$ & $\mathrm{Cra} / \mathrm{Cau}$ & $\mathrm{x}$ & \\
\hline Gato mourisco & $\mathrm{x}$ & $\mathrm{x}$ & $\mathrm{x}$ & $\mathrm{x}$ & $\mathrm{Cra} / \mathrm{Cau}$ & $\mathrm{x}$ & \\
\hline Coelho & $\mathrm{x}$ & $\mathrm{x}$ & $\mathrm{x}$ & $\mathrm{x}$ & $\mathrm{Cra} / \mathrm{Cau}$ & $\mathrm{x}$ & \\
\hline Ovino & $\mathrm{Cra} / \mathrm{Cau}$ & $\mathrm{x}$ & $\mathrm{x}$ & $\mathrm{x}$ & $\mathrm{Cra} / \mathrm{Cau}$ & $\mathrm{x}$ & \\
\hline Chinchila & $\mathrm{Cra} / \mathrm{Cau}$ & $\mathrm{x}$ & $\mathrm{x}$ & $\mathrm{x}$ & $\mathrm{Cra} / \mathrm{Cau}$ & $\mathrm{x}$ & \\
\hline Capivara & $\mathrm{x}$ & $\mathrm{x}$ & $\mathrm{x}$ & $\mathrm{Cra} / \mathrm{Cau}$ & $\mathrm{Cra} / \mathrm{Cau}$ & $\mathrm{x}$ & \\
\hline Paca & $\mathrm{x}$ & $\mathrm{Cra} / \mathrm{Cau}$ & $\mathrm{x}$ & $\mathrm{x}$ & $\mathrm{x}$ & $\mathrm{x}$ & $\mathrm{x}$ \\
\hline
\end{tabular}

O brônquio lobar cranial direito se bifurca em seis brônquios segmentares, assim encontrado também por Santos et al. (2013) em mãopelada, diferindo de quatis, que apresentam três segmentares (Santos et al., 2012). O brônquio lobar médio se bifurca em dois brônquios segmentares, corroborando os achados de Santos et al. (2013) para mão-pelada e paca (Rehder et al., 2008), porém diferencia-se dos carnívoros domésticos (Getty, 1986), da cutia (Penno et al., 2005) e do gato mourisco (Santos A. L. Q. et al., 2011), os quais não possuem bifurcação. Há ainda a origem do brônquio lobar acessório, também com a bifurcação de três brônquios segmentares, sendo que na cutia e no gato mourisco são dois brônquios segmentares (Penno et al., 2005; Santos et al., 2011a). O brônquio lobar caudal segue com sete ramificações segmentares, assim também encontrado por Santos et al. (2013) para mãopelada, assemelhando-se com a cutia (Penno et al., 2005), que apresenta de cinco a nove, e diferindo do gato mourisco (Santos A. L. Q. et al., 2011), em que e brônquio lobar caudal se subdivide em cinco brônquios segmentares. A Tab. 2 apresenta um resumo das principais características dos brônquios lobares e segmentares do pulmão dos mamíferos.

No pulmão esquerdo, o brônquio extrapulmonar esquerdo emite dois brônquios lobares, que se dirigem para o lobo cranial e o lobo caudal, também verificado por Santos et al. (2013) para mão-pelada. O brônquio lobar cranial esquerdo apresenta cinco ramificações segmentares, o que confere com Santos et al. (2013), mas difere de Sestari et al. (2011), que encontraram apenas três brônquios segmentares. O brônquio lobar caudal esquerdo se divide em três brônquios, sendo o primeiro um brônquio segmentar maior que se bifurca após a sua formação no terceiro brônquio, e o segundo um brônquio segmentar menor. Esses dados corroboram os achados para mão-pelada (Sestari et al., 2011; Santos et al. (2013), cutia (Penno et al., 2005) e gato mourisco (Santos A. L. Q. et al., 2011). Esses 
resultados diferem para paca (Rehder et al., 2008), que apresenta três brônquios lobares caudais esquerdos e um brônquio lobar acessório esquerdo (Tab. 2).

A anatomia microscópica complementa os estudos macroscópicos, uma vez que aborda estrutura e função do tecido. O tecido pulmonar é constituído por vários componentes, pouco evidenciados no presente estudo devido ao fato de os exemplares explorados serem procedentes de acidentes, assim parte dos tecidos estava em processo de autólise. As características estruturais dos brônquios principais e lobares são semelhantes às estruturas da traqueia, diferindo apenas em suas devidas proporções em menor espessura e diâmetro.

Os brônquios, em geral, apresentam um epitélio prismático pseudoestratificado ciliado, com células caliciformes e feixes de fibras de musculatura lisa dispostos longitudinalmente. $\mathrm{Na}$ camada adventícia estão presentes placas de cartilagem hialina, músculo liso e fibras elásticas (Fig. 4); essas estruturas são observadas tanto em brônquios extrapulmonares quanto em lobares e segmentares. Esses achados corroboram Banks (1991) e Samuelson (2007) em cãos e gatos, Santos A. C. et al. (2011) em quatis, Silva et al. (2012) em saguis e Ibe et al. (2011b) em ratos gigantes africanos. A histologia do parênquima pulmonar demonstra um pulmão típico de mamífero, ou seja, era essencialmente constituído de bronquíolos terminais, ductos alveolares, alvéolos, arteríolas e vênulas (Fig. 4), concordando com os achados em saguis (Silva et al., 2012).

À medida que os brônquios se ramificam, diminuem sua espessura e diâmetro, assim a camada de cartilagem hialina e as células do epitélio também diminuem, aumentando a quantidade de músculo liso e de fibras elásticas. Esse resultado foi encontrado por Banks (1991) e Samuelson (2007) em cãos e gatos, por Santos A. C. et al. (2011b) em quatis e por Silva et al. (2012) em saguis.
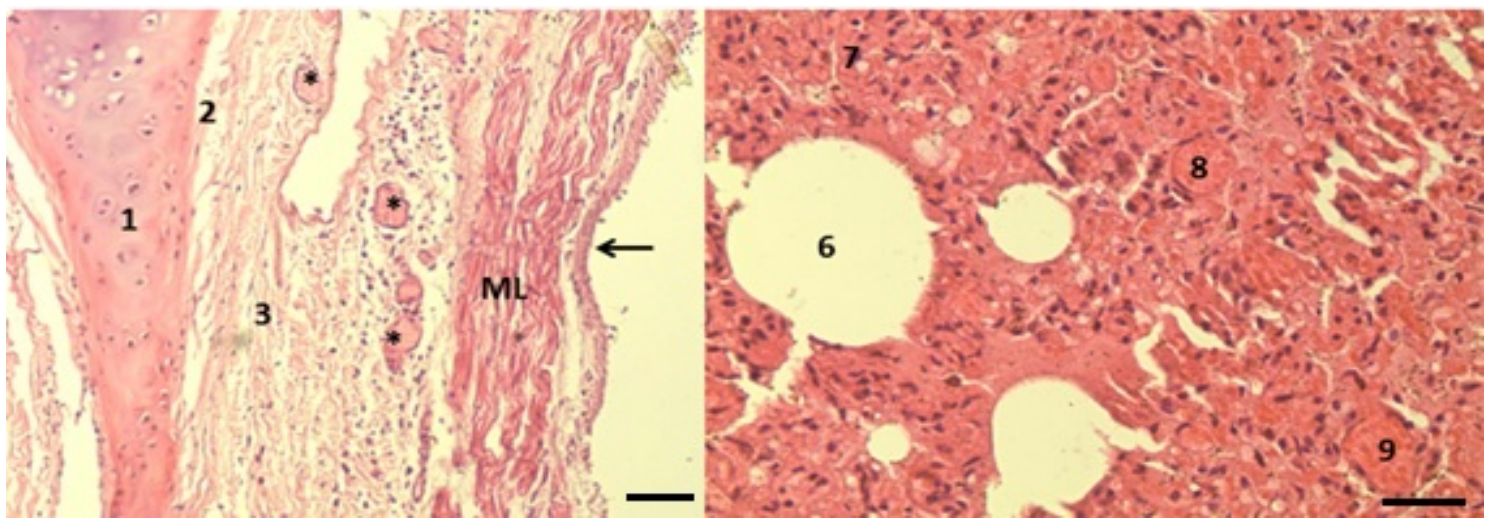

Figura 4. Fotomicrografia do brônquio principal e parênquima pulmonar de $P$. cancrivorus. Em (A) observa-se a presença de cartilagem hialina (1), pericôndrio (2), lâmina própria do tecido conjuntivo frouxo (3), vasos sanguíneos pulmonares $(*)$, feixes de fibras musculares lisas (ML) e epitélio pseudoestratificado não íntegro (seta) (Barra $=20 \mu \mathrm{m}, \mathrm{HE})$. Em (B), observam-se os bronquíolos terminais (6), os alvéolos (7), a arteríola (8) e a vênula (9). Hematoxilina e eosina. Barra $=50 \mu \mathrm{m}$.

A região de troca gasosa tem que permitir difusão eficiente de oxigênio e gás carbônico por paredes alveolares e capilares. Ao mesmo tempo, tem que resistir às forças mecânicas de insuflação pulmonar, desinsuflação e fluxo de sangue pulmonar. A capacidade de propagar oxigênio é correlacionada com as diferenças na arquitetura pulmonar entre as mais distintas espécies animais, como um índice de condutância do fluxo de oxigênio dos alvéolos para dentro dos eritrócitos nos capilares pulmonares. Entretanto, algumas estruturas são invariáveis, apesar de suas dimensões e arranjos serem influenciados por fatores funcionais dentro da relação estrutura-função do pulmão. 


\section{CONCLUSÕES}

A descrição macroscópica do pulmão do $P$. cancrivorus se assemelha, porém com algumas distinções, a todos os animais comparados e a descrição microscópica se assemelha à dos mamíferos domésticos, quati, sagui e rato gigante africano. Os resultados observados auxiliam em procedimentos anatomocirúrgicos, como lobectomia pulmonar do mão-pelada, e podem também ser utilizados em pesquisas com outras espécies, uma vez que os estudos evidenciando a anatomia pulmonar de animais silvestres demonstram grande interesse científico.

\section{AGRADECIMENTOS}

Aos professores Fabiano Sant'Ana e Alessandra F. Marcondes Viu, por auxiliarem na histologia e na fotomicroscopia, respectivamente.

\section{REFERÊNCIAS}

BANKS, W.J. Histologia veterinária aplicada. São Paulo: Manole, 1991. 629p.

BARONE, R. Anatomic comparée des mamifères domestiques. Paris: Éditions Vigot, 1997. 1021p.

BORGES, E.M.; OLIVEIRA, F.S.; MACHADO, M.R.F. et al. Segmentação anatomo cirúrgica arterial dos pulmões de ovino da raça ideal (Ovis aires, L.,1758). Braz. J. Vet. Res. Anim. Sci., v.39, p.288-295, 2002.

CÂMARA, T.; MURTA, R. Mamíferos da Serra do Cipó. Belo Horizonte: PUC-Minas/Museu de Ciências Naturais, 2003. 60p.

CITRÂNGULO, M.; RIBEIRO, A.A.C.M.; MORAES, P.T.B., MACHADO, M.R.F. Lobação e vascularização arterial do pulmão da capivara (Hydrochaeris hydrochaeris). Arq. Cienc. Vet. Zool. UNIPAR, v.4, p.119-127, 2001.

CUBAS, Z.S.; SILVA, J.C.R.; CATÃO-DIAS, J.L. Carnivora - Procyonidae (Quati, Mãopelada, Jupará), In: CUBAS, Z.S.; SILVA, J.C.R.; CATÃO-DIAS, J.L. (Eds.). Tratado de animais selvagens: medicina veterinária. São Paulo: Roca, 2006. p.432-475.
DYCE, K.M.; SACK, W.O.; WENSING, C.J.G. O membro anterior dos carnívoros. In: DYCE, K.M.; SACK, W.O.; WENSING, C.J.G. (Eds.). Tratado de anatomia veterinária. Rio de Janeiro: Guanabara, 1997. p.252-253.

EVANS, H.E.; DE LAHUNTA, A. Guia para dissecção do cão. Rio de Janeiro: Guanabara, 1994. 206p.

GETTY, R. (Ed.). Sisson and Grossman anatomia dos animais domésticos. Rio de Janeiro: Guanabara Koogan, 1986. 1480p.

IBE, C.S.; SALAMI, S.O.; ONYEANUSI, B.I. Macroscopic anatomy of the lower respiratory system in a nocturnal burrowing rodent: African giant pouched rat (Cricetomys gambianus, Waterhouse 1840). Anat. Histol. Embryol., v.40, p.112-119, 2011a.

IBE, C.S.; ONYEANUSI, B.I.; SALAMI, S.O.; NZALAK, J.O. Microscopic anatomy of the lower respiratory system of the African giant pouched rat (Cricetomys gambianus, Waterhouse 1840). Int. J. Morphol., v.29, p.27-33, 2011 b.

NOMINA anatomica veterinaria: Hannover: International Committee on Veterinary Gross Anatomical Nomenclature, 2005. 166p.

PELLANDA, M; ALMEIDA, C.M.C.; SANTOS, M.F.M.; HARTZ, S.M. Dieta do mão-pelada (Procyon cancrivorus, Procyonidae, Carnivora) no Parque Estadual de Itapuã, sul do Brasil. Neot. Biol. Conserv., v.5, p.154-159, 2010.

PENNO, A.K.; CARVALHO, M.A.M.; ASSISNETO, A.C.A. et al. Lobação, ramificação brônquica e distribuição arterial no pulmão da cutia (Dasyprocta sp., Mammalia - Rodentia). Braz. J. Vet. Res. Anim. Sci., v.42, p.331-336, 2005.

PEREIRA, R.L.; GAMBA, C.O.; RONDINI, B.T. et al. Topologia e topografia do aparelho respiratório e árvore brônquica de Chinchilla lanigera. In: CONGRESSO DE INICIAÇÃO CIENTÍFICA, 14., 2005, Porto Alegre. Anais... Porto Alegre: UFRGS, 2005. (Resumo).

PEREIRA, F.C.; LIMA, V.M.; PEREIRA, K.F. Descrição anatômica dos músculos da perna de Procyon cancrivorus (Cuvier 1798). Biotemas, v.23, p.159-165, 2010a.

PEREIRA, F.C.; LIMA, V.M.; PEREIRA, K.F. Morfologia dos músculos da coxa de mão-pelada (Procyon cancrivorus Cuvier, 1798). Ciênc. Anim. Bras., v.11, p.947-954, 2010 b. 
PEREIRA, K.F.; PARANAIBA, J.F.F.S.; HELRIGLE, C.; ARAÚJO, E.G. Origem e distribuição anatômica do nervo isquiático de mão-pelada. Pesqui. Vet. Bras., v.31, p.74-78, 2011.

PEREIRA, K.F.; SOUZA, D.R.; FERREIRA, L.S.; RIBEIRO, A.R. Aspectos morfológicos dos músculos da cabeça e pescoço do mão-pelada (Procyon cancrivorus). SaBios, v.7, p.1-8, 2012.

PEREIRA, K.F.; ARAÚJO, E.G.; SOUZA, D.R. et al. Morphological aspects of the salivary glands of crab-eating racoon (Procyon cancrivorus). Acta Sci. Biol. Sci., v.35, p.99-103, 2013.

REHDER, A.M.A.; CORTELLINI, L.A.; OLIVEIRA, F.S.; MACHADO, M.R.F. Lobação, árvore brônquica e vascularização arterial do pulmão da paca (Agouti paca, Linnaeus, 1766). Ciênc. Anim. Bras., v.9, p.442-448, 2008.

SAMUELSON, D.A. Tratado de histologia veterinária. Rio de Janeiro: Elsevier, 2007. 527p.

SANTANA, M.I.S.; SILVA, F.O.C.; BOMBONATO, P.P. et al. Estudo comparativo dos anéis traqueais em suínos (Sus scrofa Linnaeus, 1758) das raças Landrace, Large-white e Hampshire. Arq. Ciênc. Vet. Zool. UNIPAR, v.5, p.163-168, 2002.

SANTOS, A.L.Q.; MARAES, F.M.; CARVALHO, S.F.M. et al. Lobos pulmonares e formação dos brônquios do gato mourisco (Herpailurus yagouaroundi Severtzow, 1848) (Felidae). PUBVET, v.5, p.12-18, $2011 \mathrm{a}$.
SANTOS, A.C.; BERTASSOLI, B.M.; OLIVEIRA, V.C. et al. Morfologia da árvore brônquica de pulmões de quatis (Nasua nasua, Linnaeus, 1966). Biotemas, v.24, p.75-82, 2011 b.

SANTOS, A.C.; BERTASSOLI, B.M.; OLIVEIRA, V.C. et al. Lobação e segmentação brônquio pulmonar em pulmões de Nasua nasua, Linnaeus, 1766 (quatis). SaBios, v.7, p.67-73, 2012.

SANTOS, A.C.; OLIVEIRA, V.C.; BERTASSOLI, B.M. et al. Morfologia macroscópica dos pulmões e distribuição bronquiopulmonar em mão-pelada (Procyon cancrivorus). Biotemas, v.26, p.195-202, 2013.

SESTARI, C.E.O.; CORRÊA, A.F., MARTINS, L.L. et al. Lobação pulmonar e distribuição brônquica em mão-pelada (Procyon cancrivorus, Cuvier, 1798): relato de dois casos. Vet.Zootec., v.18, p.374-378, 2011.

SILVA, L.C.S.; LESSA, T.B.; SANTOS, P.R.S. et al. Arquitetura da árvore brônquica no saguide-tufo-preto: um modelo animal experimental para lesões do sistema respiratório. Arch. Vet. Sci., v.17, p.63-69, 2012. 